\title{
Research on the Cultivation of Creative Ability of Media Specialty Based on Open Experimental Teaching
}

\author{
Chuanfeng Che ${ }^{1}$ \\ Tianjin Polytechnic University
}

\begin{abstract}
Deepening the open experiment teaching after class is an effective way to improve the quality of experimental teaching and cultivate students' ability of innovation and entrepreneurship. The empirical research on the open experimental teaching of media undergraduate majors shows that the training focusing on the improvement of professional cognitive ability, practical ability, innovation ability and communication ability has the most obvious effect on the improvement of students' professional skills and innovation and entrepreneurship ability. In addition, the establishment of evaluation mechanism of different experimental training projects is also an important step to guarantee the quality of training. Therefore, the extra-curricular open experimental teaching project based on the technological development of the media industry will play a positive role in promoting the cultivation of students' innovation and entrepreneurship ability and improving the in-class experimental teaching system..
\end{abstract}

\section{Keywords}

Open Experimental Teaching $\bullet$ Cultivating Innovation Ability $\bullet$ Media Technology Application

${ }^{1}$ Correspondence to: Chuanfeng Che, School of Humanities, Tianjin Polytechnic University, Tianjin 300387, China. Email: chechuanfeng@tjpu.edu.cn

Citation: Che, C.F. (2018). Research on the Cultivation of Creative Ability of Media Specialty Based on Open
Experimental Teaching. Educational Sciences: Theory \& Practice, 18(5), 2410-2418.
http://dx.doi.org/10.12738/estp.2018.5.140


As a kind of supplement and perfection of in-class experimental teaching, extracurricular open experiment teaching is an important way to improve students' professional skills. Open experimental teaching is a kind of experimental mode different from traditional teaching. It introduces the concept of research-based learning into experimental teaching, and is open to all aspects of experimental time, space, content and teaching methods (Nie, 2017). The experimental teaching in the media undergraduate course has certain limitations in terms of time and project setting. For radio and television playwright-director, radio and television, advertising and other professional students, due to the limitation of experimental equipment and technical conditions, easy to cause the lack of professional skills upgrading auxiliary experiment practice project, so they in the mastery of professional theory knowledge is not very good at the same time to master the latest professional and technical skills. The general experimental teaching of the media undergraduate major is combined in a certain course, and the experiment number of each course is usually 1-2, and both are carried out in groups. Therefore, students can only understand the degree, but cannot meet the requirements of having certain professional skills. In the 1950s, foreign countries began to carry out the research of extracurricular open experiment and auxiliary teaching, and began to be accepted by education field in the early 1960s. At that time, many reform ideas and plans were proposed, represented by American extracurricular experimental teaching reform of physics.

In recent years, the digital media experiment center of Tianjin University of technology has actively explored the extracurricular open experiment training program for media students of different grades and majors through the basic experimental teaching process. We found that there is a general lack of understanding of the professional skills that should be mastered in the future of the major in the junior grade of the major of media. Students in the middle and higher grades lack the practical ability and operational ability of the media technology and equipment, while students in the higher grades lack the ability of external communication and self-expression. Therefore, on the basis of the in-class experimental teaching every semester, we strive to explain the technical knowledge related to the major clearly through a certain number of extra-curricular special experimental training programs, so that students can greatly improve their understanding of the theoretical knowledge and professional technical knowledge of the major.

\section{Construction of open experimental platform of digital media experimental center}

Cultivating the innovative spirit and ability of college students is not only an important task of college experimental teaching, but also an eternal theme of experimental teaching (Yan, Zhang \& Jin, 2010). However, experimental teaching is greatly influenced by the experimental conditions, experimental teachers and experimental environment, and the lack of these conditions will directly affect the cultivation of high-quality talents (Zhang, Xia, Lu \& Pan, 2015). Radio and TV industry is an industry with intensive application of new technologies. Cloud storage, cloud editing, cloud release and other emerging production and broadcasting technologies featuring Internet cloud technology are being rapidly applied to the industry. In the face of the continuous application of new technologies in the industry, the media specialty of institutions of higher learning needs to further strengthen the experimental teaching on the basis of the previous teaching mode, and constantly expand the ways and methods of cultivating innovative ability. The digital media experimental teaching center 
of tianjin university of technology takes journalism and communication, drama, film and television as the subject foundation, and supports the special place for basic and comprehensive experimental teaching of radio and television, radio and television editing and directing, advertising and other media majors. Experiment center since its establishment continuously strengthen and improve the experimental teaching platform and the construction of experimental teaching system, from the media convergence in the light of the demand of the era of applied media talents, always adhere to the cultivation of students' innovative ability, new technology application in digital media industry to talented person's demand as the guidance, reasonable planning, scientific experiment course and content, digital media training students' practical ability, and the application of new media and design ability, while strengthen the students theoretical basis, strengthen students in the field of transmission filming, recording, editing, broadcast and release and so on various aspects of practical ability training.

\section{Open Experimental Projects Focusing on The Improvement of Professional Cognitive Ability}

Providing students with a relatively open environment and a place for innovation and practice is the source of knowledge innovation and the base for training scientific and technological talents (Liu \& Wang, 2016). For freshmen, because they do not have the knowledge of specialty and so on to ensure basic experimental teaching in the class, on the basis of the experiment center of freshmen on the professional cognition promoted as the core of openness to strengthen experimental training program, the purpose is to fit each professional introduction to "professional" "introduction to radio and television" introduction to "advertising" courses, to let the students into professional laboratory, in the form of PuXun causes the student to quickly understand the professional training content, professional development direction in the future and their future should have professional ability. This kind of open experimental project includes: digital studio laboratory cognitive experience experiment; Virtual studio cognitive experience experiment; Photographic laboratory cognition experience experiment; These four training programs are appreciated for students' works over the years. The duration of each program is 4 to 6 hours, which is conducive to the rapid formation of students' cognition of this major.

\section{Open Experimental Projects Focusing on The Improvement of Professional Operational Ability}

In previous theoretical and experimental teaching process, we found that not every student can completely adapt and recognized their own professional, not good professional equipment operation, and even conflicting situation, the main reason was partly due to students themselves don't like the operating equipment, on the other hand is the existing class time is not enough, can't do everyone the opportunity to practice, especially into the sophomore, gradually opened the TV camera, photography art and technology, advertising photograph, nonlinear editing and television editing practical courses, the students of differentiation appeared gradually, so the experiment center in view of the situation, Additional courses are offered to supplement open experimental projects, which can effectively enhance students' practical ability. Such projects include: basic operation training of photographic equipment; Basic operation training of camera equipment; Video program editing intensive training; 
Extracurricular Experimental Projects Focusing on The Improvement of Professional Innovation Ability

Innovative experiment is the "soul" of the whole experimental teaching reform (Kuang, Liu, Zhong, \& Cheng, 2012). In developing open experimental project, digital media experiment center for the junior students, the main consideration to strengthen and improve the students' practical ability and innovative ability of professional training, such experimental training program mainly as a television program planning, program editing and programme production, television program director, film and TV aesthetics such as course experiment supplement and improve. Project details include: news panorama photo shooting and modification training; Color application training for film and television editing; Multi-position video editing application training; Training of news interview programs on multiple planes; Four experiments were conducted, including lighting and lighting application intensive training. The duration of each project was about 8 hours. Students selected corresponding experimental projects according to their own interests and required students to submit experimental works as the assessment basis at the end of the project.

\section{Extracurricular Experimental Projects Focusing on Improving Communication Skills}

Laboratory construction is a long and arduous task, and it is the responsibility of current laboratory work to find out the mode of laboratory teaching and training suitable for the development of applied talents (Liu, 2012). To enter the senior students, after three years of professional learning, have certain theoretical knowledge and professional skills, they need most is to these knowledge and skills into the ability of practical application, and be able to have the ability to express and communication, so in the senior stage need to increase the communication ability of intensive training program. Such open experimental training programs include: TV program simulation training; Training for journalists who appear on camera; Through these open experimental projects, students can greatly improve their ability in the use of skills and communication with foreign countries.

\section{Open experimental training project assessment and evaluation}

How to evaluate the effect of opening experiment project, to better promote experiment teaching and theory teaching in class, has been the important research topic of open experiment teaching reform at colleges and universities, digital media experiment center of tianjin university of technology based on an open experimental teaching experience in recent years established a relatively comprehensive assessment and evaluation mechanism.

\section{Assessment Methods for Open Experimental Projects}

The open experimental training project with the goal of improving professional cognitive ability is mainly designed to test students' cognitive degree of the major. Therefore, the assessment method is to require students 
to complete a professional cognitive report of about 800 words, and the open experimental instructor is responsible for evaluating the reports completed by students. To improve professional adaptability

The purpose of the open experimental project is to test students' adaptability to their major. Therefore, the assessment method requires students to complete corresponding experimental reports according to different experimental projects, and it mainly allows students to summarize their own experience in completing experimental projects. The open experimental project with the purpose of improving professional innovation ability is mainly to test students' practical ability and innovation ability. Therefore, the assessment method is to require students to complete an independent experimental work according to different experimental projects. For the open experimental project aiming at improving communication and expression ability, the assessment purpose is mainly to test students' ability to express and communicate with the outside world. Therefore, the assessment method requires students to complete an experimental work in the role of host or journalist.

\section{Evaluation Mechanism of The Effect of Open Experimental Project}

Open experimental teaching means that all experimental resources are open to students in experimental teaching, so that students become the subject of experiments and realize students' independent experiments (Yu, Wang, Zhao \& Chen, 2011). Since students are expected to conduct independent experiments, the evaluation of the effect of open experimental teaching should be conducted from the following three aspects. First, whether students have a deeper understanding of the content of in-class experiments and theoretical teaching after the open experimental project training. The second is whether the students have improved their understanding of the major and media industry through the open experimental project. The third is whether the students' innovation ability can be improved through the open experimental project training. So in the above three, digital media experiment center set up a set of scientific and reasonable evaluation mechanism, and establishing the evaluation index system, organize regular school each semester real test full-time teachers and industry, and after the opening experiment of different grade students to complete the project report submitted by the experiment, experiment works, communication skills, such as special assessment content, and organize the students to view and communicate with each other, will receive a grade prize of learning

The students' works were exhibited to obtain the effect of the open experimental project on students.

\section{Relying on the innovation laboratory of college students to further expand the way of open experimental teaching}

The cultivation of innovative talents needs to be realized through innovative education, among which innovative experiment is an important way to cultivate students' practical ability and innovation ability (Sheng, 2011). In 2015, with the approval of the school, our school officially established the digital media innovation laboratory. The establishment of the laboratory is closely centered on the cultivation of students' innovation ability and practical ability. Through opening experimental teaching resources, the laboratory organizes and supports students to participate in various competitions, so as to achieve the goal of promoting training and 
improving professional skills through competitions. By supporting and serving teachers and students to carry out scientific research projects and college students' innovation and entrepreneurship projects, further cultivating students' innovation awareness, entrepreneurial ability and creative practice ability, and further promoting students' enthusiasm and self-consciousness to participate in practical creation. At present, the major media competitions supported by the innovation laboratory of our university include: Tianjin college students' computer application ability contest -- campus micro video competition; Advertising competition for Chinese college students; Times "golden calf award" advertising contest; Tianjin wenming office micro video competition; Over the past three years, the Beijing university students film festival and other high-level competitions have won more than 300 national, provincial and municipal awards. Since the establishment of the innovation laboratory, teachers and students have been actively supported to carry out various scientific research projects, national university student's innovation and entrepreneurship projects.

\section{Problems and countermeasures in open experimental teaching}

The cost of laboratory opening increases greatly, but the fund is insufficient, the workload of teachers increases, and the enthusiasm of students to enter the laboratory is not high (Hou \& Zhang, 2011) Is a common problem in laboratory opening. On the basis of ensuring the basic experimental teaching in each semester, the digital media experimental center provides students with relatively open experimental environment and places for innovative practice. However, there are inevitably some problems in the process of open experimental teaching, which are embodied in the following aspects: 1 . Second, lack of professional experimental instructors; Third, open experimental projects often require students to use their spare time to complete, so it is difficult to achieve time unity; Fourth, it increases the work burden of the existing equipment and personnel in the laboratory.

\section{Change the Concept and Increase the Improvement and Upgrade of Experimental Equipment}

Experimental equipment and funds are the foundation of the laboratory opening, which is also the inevitable problem of the open laboratory. It determines the scope and quality of the laboratory opening. With the rapid pace of upgrading of technology and hardware equipment in the media industry, the demand for radio and television media talents is higher and higher. In order to adapt to the actual situation of rapid development in the industry, we must adjust the teaching methods and models in time and constantly strengthen the proportion of experimental teaching. School to change the former to liberal arts majors, funds investment and the proportion of the strength experiment center also to fully excavate the potential of experimental sites, instruments and equipment, with the social demand as the guidance, strengthening the management of the experiment center and make full use of much starker choices-and graver consequences-in planning investment, special laboratory construction funds and other investment opportunities, update experimental teaching instruments and equipment, improve the experimental teaching environment, and make full use of the school of other related disciplines, such as animation and other professional hardware resources, effective use of resources of the school, the school resources sharing. 


\section{Strengthen the Construction of Experimental Teaching Faculty}

The construction of university experimental teaching team is the key of experimental teaching (Zhang, Wang \& Ma 2010). Our digital media experiment center is mainly for radio and television, radio and television playwright-director, advertisement the three undergraduate programs, the main experimental teachers are from the three professional theory of teachers' team, only a small amount of full-time experiment teachers, and the theory of teacher is often due to these stress from teachers' teaching and research, and participate in practice, thus forming the theory of experimental teachers weighs theory practice. In view of this situation, the college should be aware of creating a double-division experimental teaching team combining theory and practice. An excellent research group and experimental teachers with high academic level, reasonable age structure, knowledge structure, academic structure and professional title structure and strong innovation ability are the fundamental guarantee for the long-term development of the laboratory and the sustainable development of scientific and technological innovation research (Zeng \& Chen, 2012). The experimental teachers should be encouraged to guide the students to declare the undergraduate innovation and entrepreneurship training project and the university student's science and technology innovation project with the content of the open experimental project, so as to further improve the research level and guidance ability of the experimental teachers.

\section{Strengthen the Experimental Teaching Research and Improve the Experimental Teaching Level}

Traditional experimental teaching neglected the cultivation of students' interest (Wang, Du \& Xu, 2012) Open experimental teaching aims to improve students' interest and innovative practical ability and conducts experimental teaching continuously and deeply. Universities in developed countries such as the United States and Japan have long put forward the idea of open curriculum teaching and the method of open experimental teaching to cultivate college students and postgraduates of different disciplines, majors and levels (Kong, 2012). Open experimental teaching has built a bridge for students to participate in scientific research. Many undergraduate students have learned about the general process of scientific research through open experiments, gained some perceptual knowledge about scientific research, and developed interest in scientific research (Wang, Gao, Shi \& Fan, 2011). Thus, to improve the effect of media class of open experimental teaching, we must through pay close attention to the development of high and new technology industry dynamic, constantly enrich and improve the existing experimental content and level of the project, teachers guide students to take an active part in open experiment project development subject, jointly promote open experiment pertinence and practicability of the project. The extracurricular innovation platform is the extension of classroom teaching and the integration of theory and practice, knowledge and ability. It can comprehensively cultivate students' innovative consciousness and spirit (Zou \& Xia 2010). In order to cultivate students' innovation ability, we have strengthened the opening up of enterprises and laboratories, turned the practical problems of enterprises into research projects, and closely combined with enterprises to implement school-enterprise collaborative innovation, serve the local area, and open up new ways for school-enterprise cooperation to cultivate students' innovation ability (Ouyang, Jiang \& Wang, 2016). Open experimental teaching breaks the traditional closed 
experimental teaching mode, complies with the development requirements of modern education, and plays a positive role in cultivating students' innovative ability and comprehensively improving teaching quality.

\section{Conclusion}

As an important part of cultivating innovative talents, the open training program of media specialty laboratory is an important means to promote students' interest in learning and all-round learning. Our digital media experiment center according to the actual situation of the industry development training program developed by the extracurricular experiment, its purpose is to hope that through a PuXun nature of the training project, can better stimulate students learning enthusiasm and initiative, and on this basis, between teachers and students improve each other and learn from each other is formed between the virtuous circle of a closed loop. But everything has two sides, the training mode while in the aspect of knowledge and mutual exchanges played a good role in promoting, but on the other hand also will expose the insufficiency, the experimental equipment and equipment industry is no longer a level, guide teacher shortage and inadequate experience, laboratory management difficulty increases, the training time is short. Only by better solving these problems, fully exploring the resource advantages of the laboratory, and further enriching the connotation construction of the open experimental training project and the establishment of the evaluation index system, can excellent innovative media talents be cultivated for the society.

\section{References}

Hou, F.C., \& Zhang, G.H. (2011). Analysis of problems and countermeasures in university laboratory opening. Experimental Technology and Management, 28(1), 177-179.

Kong, P. (2012). Research on open experimental teaching in comprehensive experimental teaching center of liberal arts. Experimental Technology and Management, (6), 130-131+135.

Kuang, C.P., Liu, S.G., Zhong, G.H., \& Cheng, S.B. (2012). Experimental teaching reform and cultivation of students' innovation ability. Laboratory Research and Exploration, 31(9), 86-88.

Lin, Z.Q. (2012). Construction of innovative laboratory based on the cultivation of applied talents. Journal of Jiaying College: Philosophy and Social Sciences, 30(3), 91-93.

Liu, X.H., \& Wang, F.Y. (2016). Exploration of laboratory open mode with innovative talent cultivation as the core. Experimental Technology and Management, (1): 9-12. http://dx.doi. org/ 10.16791/j.cnki.sjg.2016.01.003

Nie, J.W. (2017). Exploration of open experimental teaching reform in radio and television editing and directing. Audio-visual, (11), 227-228.

Ouyang, Y.Z., Jiang, J.B., \& Wang, G.C. (2016). Experimental teaching reform and practice in the context of collaborative innovation. Laboratory Research and Exploration, (01), 173-175+205.

Sheng, S.Y. (2011). Practice of innovative experimental project construction. Laboratory Research and Exploration, 30(9), 107-109.

Wang, Q.W., Du, Y.P., \& Xu, S.M. (2012). Problems and countermeasures after the laboratory opening. Experimental Technology and Management, 29(3), 337-339. 
Wang, X.G., Gao, Y., Shi, L., \& Fan, Y.J. (2011). Theory and practice of open experimental teaching. Laboratory Science, (08), 73-75.

Yan, J., Zhang, C.G., \& Jin Q.F. (2010). Application of PBL teaching method in experimental teaching reform of fine chemical synthesis. Experimental Technology and Management, 27(7), 151-153.

Yu, Z.H., Wang, Y.T., Zhao, J. \& Chen, X.C. (2011). Exploration and practice of building open experimental teaching system. Experimental Technology and Management, 11(28), 141-143.

Zeng, X.S., \& Chen, Q. (2012). The correlation between laboratory openness and sharing and independent innovation ability. Experimental Science and Technology, 10(6): 164-167.

Zhang, X., Wang, Y.M., \& Ma, W.Q. (2010). Development, changes and characteristics of experimental teaching teams in universities. Laboratory Research and Exploration, (02), 160-162. http://dx.doi. org/10.3969/j.issn.1006-7167.2010.02.051

Zhang, X.Y., Xia, X.Y., Lu, J., \& Pan, X.J. (2015). Research and practice of mechanical experimental teaching reform based on laboratory opening. Experimental Technology and Management, (10), 161-163.

Zou, G.P., \& Xia, X.Y. (2010). On the cultivation model of college students' innovation ability. Heilongjiang Higher Education Research, (3), 128-129. http://dx.doi. org/10.3969/j.issn.1003-2614.2010.03.040 